\title{
The effect of caster wheel diameter and mass distribution on drag forces in manual wheelchairs
}

\author{
Rene Zepeda, BEng; ${ }^{1}$ Franco Chan, BASc; ${ }^{2}$ Bonita Sawatzky, PhD $^{2-3^{*}}$ \\ ${ }^{1}$ Department of Technological and Industrial Processes, Instituto tecnológico y de estudios superiores de occidente, \\ Jalisco, Mexico; ${ }^{2}$ International Collaboration on Repair Discoveries, University of British Columbia, Vancouver, Can- \\ ada; ${ }^{3}$ Department of Orthopaedics, Faculty of Medicine, University of British Columbia. Vancouver, Canada
}

\begin{abstract}
This study proposes a way to reduce energy losses from rolling resistance friction during manual wheelchair propulsion by increasing the size of the front caster wheels and adjusting the weight distribution. Drag tests were conducted using a treadmill and a force transducer. Three different caster diameters (4 in., 5 in., and 6 in.) and six different mass distribution combinations (based on percentage of total weight on the caster wheels) were studied. A two-way analysis of variance test was performed to compare caster size and weight distribution contribution with drag force of an ultralight wheelchair. The 4 in. caster contributed significantly more drag, but only when weight was $40 \%$ or greater over the casters. Weight distribution contributed more to drag regardless of the casters used.
\end{abstract}

Key words: caster wheel, drag force, drag test, efficiency, friction, rolling resistance, treadmill, weight distribution, wheelchair, wheel diameter.

\section{INTRODUCTION}

The prevalence of wheelchair users has increased as the aging population continues to expand across the globe [1]. Studies conducted in Canada [2], France [3], the United Kingdom [4], and the United States [5] have demonstrated that many elderly people rely on wheelchairs to live independently in the community. The most commonly used method of wheelchair propulsion is manual hand rim propulsion [6]. The repetitive nature of this movement makes users prone to pain in their upper limbs and trunk [7]. The percentage of wheelchair users reported to suffer from shoulder pain has ranged from 37.5 to 78.0 percent [8-11] in different studies on individuals with paraplegia and quadriplegia. Hand and elbow pain has been reported in as many as 43 percent [10] of wheelchair users, while 73 percent of wheelchair users have reported back pain [11].

Manual wheelchair use, just like walking, happens in "bouts of activity" [12]. Roughly 63 percent of these bouts are distinguished by slow and short changes in speed and direction, which require more energy than the energy needed to maintain a constant velocity. The wheelchair rider must surmount the initial inertia and alter the momentum of the wheelchair-user system several times per day. On average, the rider performs 10 bouts of activity for each hour seated in the wheelchair, which may subsequently lead to the distresses stated previously. To reduce these discomforts, it is important to educate wheelchair users about the optimal

\footnotetext{
Abbreviations: ANOVA = analysis of variance, ICC $=$ interclass correlation coefficient.

*Address all correspondence to Bonita Sawatzky, PhD; International Collaboration On Repair Discoveries, University of British Columbia, $818 \mathrm{~W}$ 10th Ave, Vancouver BC V5Z 1M9, Canada; +1-604-675-8806.

Email: bonita.sawatzky@ubc.ca

http://dx.doi.org/10.1682/JRRD.2015.05.0074
} 
usage and configuration of their wheelchair [13], such as changing their propulsion technique or sitting in a rearward position on the chair. Nonetheless, manual wheelchair propulsion is not a very efficient method of mobility per se. The ratio between power applied to the hand rim and power obtained in the form of movement of the wheelchair is notably low, with values ranging between 2.0 to 10.5 percent [14-19], compared with mechanical efficiencies of 18 percent to 23 percent for cycling [20] and 20 to 40 percent for walking [21-22].

Studies have been conducted with the goal of improving the efficiency of the current wheelchair design to decrease energy consumption during wheelchair propulsion. Specifically, the mass of the wheelchair has been evaluated by comparing the standard wheelchair with an ultralight wheelchair. Beekman et al. [23] and Cowan et al. [24] verified that using an ultralight wheelchair resulted in higher speeds and lower oxygen consumption from the user. The use of different types of rear wheelchair wheels was also addressed by Gordon et al. [25], Sawatzky et al. [26], and de Groot et al. [6], who demonstrated the benefits of using pneumatic tires compared with using solid airless tires. These benefits included a reduction in the rolling resistance force, which constitutes a large component of the drag force that must be overcome by the user to move the wheelchair and consequently, the power needed from the user to generate speed in the wheelchair.

An important component of the efficiency puzzle that has long been forgotten is the caster wheels, which are responsible for turning and rotating the wheelchair. Normally, caster wheels are small in order to facilitate the yaw rotation of the wheelchair for its use indoors, because furniture and objects close to the floor can interfere with the yawing movement of the wheels. However, the small size of the casters may bring other disadvantages to wheelchair users. From Rabinowicz's laws of rolling friction [27], the rolling resistance force varies inversely with the radius of curvature of the rolling object and surface. Thus, it can be inferred that energy losses from this phenomenon are prominently present in the front caster wheels because of their small radii, increasing as supported load increases. The authors acknowledge that smaller wheel radius does play a role in rolling resistance over rougher surfaces, such as gravel, because larger wheels help leverage the chair over small bumps on the ground. However, it is important to explore the question of caster size and load distribution on smooth surfaces before analyzing the effect of this component on various rough surfaces. In previous studies, the results obtained when analyzing wheeling on rough surfaces have shown higher numbers in terms of amount of energy required from the user to maintain a constant velocity than when wheeling on smooth surfaces $[24,28]$. Nonetheless, it is hard to determine the role of the front wheels on rough surfaces, considering that the friction coefficient on these surfaces is considerably higher than on smooth surfaces. This could make the hypothetical benefits of making adjustments to the size of the caster wheels almost insignificant for rough surfaces. In addition, many older individuals living in residential care spend 90 percent of their time indoors on smooth surfaces; thus, a study examining smooth surface rolling resistance would be relevant. Determining the optimum set of casters and percentage of load supported by them without compromising the safety of the rider, as a center of mass closer to the front end would make the wheelchair unstable [24,29-30], could ameliorate the energy loss and improve the overall mechanical efficiency of the wheelchair. The purpose of this study was to determine the role of the caster wheels in the drag force of a wheelchair on a smooth level surface.

The two hypotheses are-

1. That caster wheels with larger diameters will reduce the total rolling resistance force of a wheelchair, and,

2. That rolling resistance will be different between three caster sizes as the percentage of the total weight supported by the casters increases.

This study proposes the use of a treadmill to measure the drag forces, recognizing that the smoothness of the treadmill belt will not match the exact same smoothness of common indoor smooth surfaces, such as linoleum, wood, or tile. The treadmill represents a convenient way of reducing and controlling certain variables (i.e., air drag force, constant velocity), as well as greatly reducing the physical space needed to perform a drag test.

\section{METHODS}

\section{Procedure}

A series of drag tests using a motor-driven treadmill (Max Mobility; Antioch, Tennessee) and a rigid frame, ultralight wheelchair (TiLite; Pasco, Washington) (10 kg) were performed following the procedure initially described by van der Woude et al. [15] and used more 
recently by de Groot et al. [31]. The drag tests had two variable factors: diameter of the caster wheel and center of mass of the wheelchair-weight system (represented in weight distribution). Other components of the wheelchair, such as the rear wheels and caster forks, were kept constant in order to isolate the effects of the variables mentioned previously. Before the start of each trial, the rear wheels' tire pressure was set at $700 \mathrm{kPa}$ (approximately $100 \mathrm{psi}$ ). A set of front casters was installed on the wheelchair and a dummy weight of $60 \mathrm{~kg}$ (typical female adult weight) was placed on the seat. To modify the weight distribution (percentage of total weight on caster wheels), the distance of the dummy weight relative to the posterior and anterior wheelchair axles was adjusted before the start of each trial, using a wheelchair scale to measure the weight supported by the front caster wheels, starting at 10 percent of the total weight of the system and increasing by 10 percent for each subsequent set of tests up to 60 percent.

After adjusting the weight distribution, we placed the wheelchair on the motor-driven treadmill while forces were measured using a calibrated force transducer (OMEGA Engineering; Stamford, Connecticut) firmly mounted to the frame of the treadmill (Figure 1) and attached to the frame of the wheelchair using a rope. The incline relative to the treadmill surface and position of the rope were consistent during all the tests performed. Three trials were performed at a linear velocity of $1.111 \mathrm{~m} / \mathrm{s}$, registering the drag force at different inclines of the treadmill, from 5.5 percent to 0.5 percent, reducing the incline by 0.5 percent for each measurement. The drag force at 0 percent incline was calculated by linear regression using the data collected during the three trials per condition.

\section{Rear and Caster Wheels}

A single ultralight wheelchair was used during the test. The wheelchair was equipped with two $609.6 \mathrm{~mm} \times$ $25.4 \mathrm{~mm}$ (24 in. $\times 1$ in.) TiLite Shadow rear wheels with Schwalbe Marathon Plus tires (Schwalbe; Reichshof, Germany). These wheels presented a neutral camber $\left(0^{\circ}\right.$ angle). The front casters chosen for the study (Table 1) were new at the moment of the test and had polyurethane tires. Inside the casters, new bearings were properly installed to ensure uniform rotational movement. The caster stem was not adjusted during the drag tests because no apparent difference was observed in the inclination of the stem between the three caster sets.

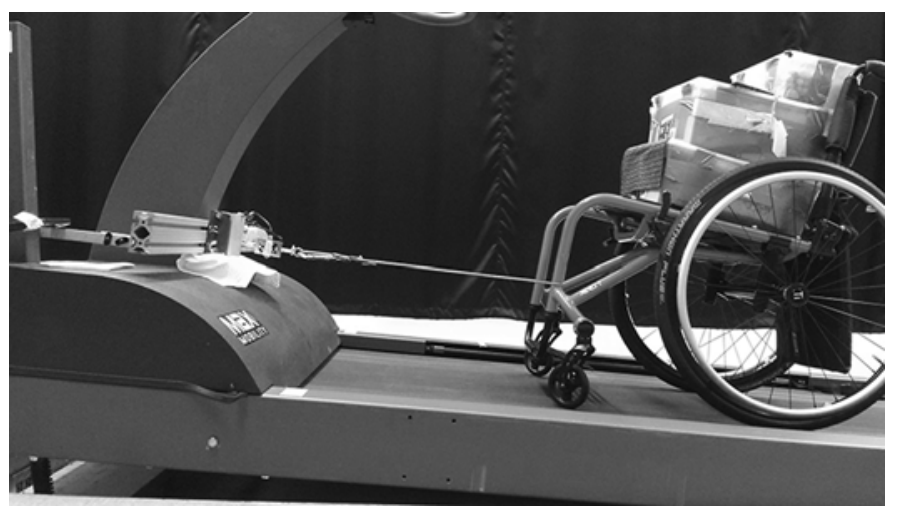

Figure 1.

Set-up of drag test with the ultralight wheelchair mounted on the treadmill. Dummy weight (weight boxes) is positioned, and the frame of the wheelchair is connected by a rope to the force transducer.

\section{Drag Force}

The drag force needed to be overcome during wheelchair propulsion is composed mainly of the rolling resistance force $\left(F_{\text {roll }}\right)$, air resistance force $\left(F_{\text {air }}\right)$, internal friction $\left(F_{\text {int }}\right)$, and force of gravity [7]. Drag force is calculated as-

$$
\text { Drag Force }=F_{\text {roll }}+F_{\text {air }}+F_{\text {int }}+(m \times g \times \sin \alpha) \text {, }
$$

where $m=$ mass of the system (in our test, mass of the wheelchair + weight boxes), $g=$ acceleration due to Earth's gravity, and $\alpha=$ slope of the surface (where the wheelchair rolls).

Linear acceleration was presumed as 0 (constant speed). Air friction and internal friction losses were assumed as nonsignificant in order to focus the study on the rolling resistance phenomena. To dispense the force of gravity component in Equation 1, the drag force at 0 percent incline $\left(\alpha=0^{\circ}\right)$ was calculated. This value was assessed by performing linear regression using the average

Table 1.

Specifications for each set of caster wheels tested. Values correspond to a single caster.

\begin{tabular}{lccccc}
\hline \multicolumn{1}{c}{ Caster } & $\begin{array}{c}\text { Diameter } \\
\mathbf{( m m )}\end{array}$ & $\begin{array}{c}\text { Profile } \\
\mathbf{( m m )}\end{array}$ & $\begin{array}{c}\text { Weight } \\
\mathbf{( k g )}\end{array}$ & $\begin{array}{c}\text { Width } \\
\mathbf{( m m )}\end{array}$ & $\begin{array}{c}\text { Footprint } \\
\text { Area }\left(\mathbf{m m}^{2}\right)\end{array}$ \\
\hline 4 in. $\times 1$ in. & 101.60 & 6.75 & 0.15 & 19.5 & 101.86 \\
5 in. $\times 1$ in & 123.83 & 12.75 & 0.20 & 25.3 & 195.82 \\
6 in. $\times 1$ in. & 142.88 & 22.40 & 0.25 & 25.9 & 151.57 \\
\hline \hline
\end{tabular}


from the values collected during the three trials per condition, as described in more detail by de Groot et al. [31]. The maximum error in the linear regression from each trial was registered, maintaining an absolute error value $\leq 1.75 \mathrm{~N}$.

\section{Statistics}

The effects of the independent variables (caster wheel diameter and weight distribution) on the drag force were analyzed using a two-way analysis of variance (ANOVA) test. Two additional tests of simple effects were also performed after a significant interaction between the two variable groups was found. These tests revealed the significant effect on drag force of the first variable group at a fixed, single factor of the second variable group.

To validate consistent results across the three trials performed for each test configuration, an interclass correlation coefficient (ICC) test was conducted. ICC singlemeasurement values $\geq 0.95$ were considered acceptable for test purposes to show reliability. The analysis showed values higher than 0.99 across each configuration.

All the statistical tests were performed using SPSS version 22.0 (IBM; Armonk, New York). A confidence interval of 95 percent was set for all statistical tests.

\section{RESULTS}

The two-way ANOVA test discovered $p$-values $<0.05$ for both independent variable groups and their interaction, indicating a statistically significant effect on drag force.

\section{Interaction Between Factors}

The two-way ANOVA test displayed an interaction between the independent variable groups "casters wheel diameter" and "weight distribution" ( $p<0.001)$, meaning dependence between the two variables. A significant jump in the drag force values (Figure 2) while using the

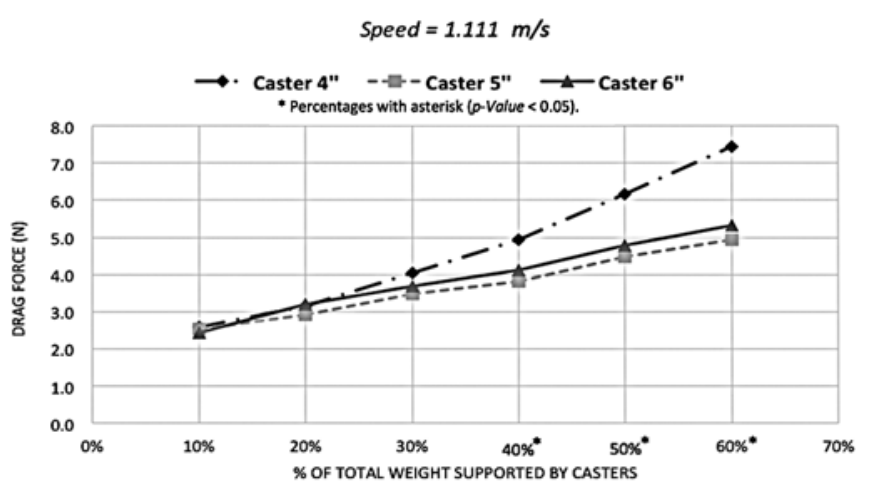

Figure 2.

Drag force at an incline of $0 \%$ plotted against percentage of total weight supported by the caster wheels. A constant speed of $1.111 \mathrm{~m} / \mathrm{s}$ was maintained during data acquisition. Total weight supported: $688 \mathrm{~N}$.

smallest caster set occurred at 40 percent of weight support (i.e., $4.93 \mathrm{~N}$ compared with $3.81 \mathrm{~N}$ and $4.12 \mathrm{~N}$ with a linear velocity of $1.111 \mathrm{~m} / \mathrm{s}$ ) (Table 2), distancing itself from the other two sets of casters. This difference continued to increase until reaching the maximum percentage value (60\%) of weight support tested (i.e., $7.45 \mathrm{~N}$ compared with $4.94 \mathrm{~N}$ and $5.31 \mathrm{~N}$ with a linear velocity of $1.111 \mathrm{~m} / \mathrm{s}$ ) (Table 2).

Two additional simple effect tests were performed after the interaction between factors was confirmed. The variable "caster wheel diameter" was only significant when presenting values of percentage of weight supported by casters equal to or higher than 40 percent (Table 3). On the other hand, the variable "weight distribution" was significant across all three factors of the "caster size" variable ( $p<0.001$ for 4 , 5, and 6 in.), showing that, regardless of the diameter size of the caster set, the weight distribution is a critical factor in drag force.

Table 2.

Mean \pm standard deviation drag force $(\mathrm{N})$ at $0 \%$ incline for each test configuration at a linear speed of $1.111 \mathrm{~m} / \mathrm{s}$. Total weight supported: $688 \mathrm{~N}$.

\begin{tabular}{lcccccc}
\hline \multirow{2}{*}{ Caster } & \multicolumn{5}{c}{ Weight Supported (\%) } \\
\cline { 2 - 7 } & $\mathbf{1 0}$ & $\mathbf{2 0}$ & $\mathbf{3 0}$ & $\mathbf{4 0}$ & $\mathbf{5 0}$ & $\mathbf{6 0}$ \\
\hline 4 in. & $2.584 \pm 0.127$ & $3.150 \pm 0.185$ & $4.033 \pm 0.430$ & $4.934 \pm 0.110$ & $6.166 \pm 0.169$ & $7.455 \pm 0.307$ \\
5 in. & $2.523 \pm 0.433$ & $2.928 \pm 0.137$ & $3.481 \pm 0.404$ & $3.811 \pm 0.552$ & $4.488 \pm 0.158$ & $4.944 \pm 0.450$ \\
6 in. & $2.420 \pm 0.225$ & $3.201 \pm 0.342$ & $3.689 \pm 0.321$ & $4.125 \pm 0.436$ & $4.787 \pm 0.441$ & $5.314 \pm 0.449$ \\
\hline \hline
\end{tabular}


Table 3.

Significance ( $p$-values) from a simple effects test for the variable group "caster wheel diameter" at a specific factor of "weight distribution."

\begin{tabular}{lc}
\hline \multicolumn{1}{c}{ Weight Distribution (\%) } & $\boldsymbol{p}$-Value \\
\hline 10 & 0.84 \\
20 & 0.59 \\
30 & 0.15 \\
40 & $\mathbf{0 . 0 0 1}$ \\
50 & $<\mathbf{0 . 0 0 1}$ \\
60 & $<\mathbf{0 . 0 0 1}$ \\
\hline Note: Bold indicates statistical significance effect on the dependent variable.
\end{tabular}

\section{Caster Wheel Diameter}

A change in the caster wheel diameter showed an effect on the drag force $(p<0.001)$. A pairwise post hoc Tukey range test revealed statistical significance when comparing the smallest caster tested (4 in.) with both the 5 in. caster and 6 in. caster ( $p<0.001$ for both comparisons). There was no statistical difference between the $5 \mathrm{in}$. caster and 6 in. caster $(p=0.13)$ for drag force. This significance was not independent from the weight distribution variable.

\section{Weight Distribution}

Different percentages of weight supported by the front casters showed to have a significant effect $(p<$ 0.001 ) in the drag force measured. Drag force augmented as weight supported by the caster wheels did the same (Figure 2). This significance was not independent from the caster wheels variable.

\section{DISCUSSION}

\section{Caster Wheel Diameter}

As expected, the rolling resistance force changed depending on the caster wheel diameter. The smallest caster tested showed significantly larger drag forces, but only when supporting 40 percent or more of the total load. It was not possible to accept the first hypothesis because the largest caster wheel tested did not show a significant difference on the rolling resistance force compared with the medium-size caster wheel. This study was limited to one feature of the caster wheels: the diameter. Other characteristics of the caster wheels, such as tire width, height of profile, tire hardness, footprint size, etc., could have a meaningful effect on the drag force. To minimize the influence of these factors, the three sets of cast- ers chosen were from the same brand, had the same rim, and were made from the same material (polyurethane); all were new at the beginning of the study.

The results of this study agree with the conclusions reached by Kauzlarich and Thacker [32], Frank and Abel [33], and Brubaker [29]. The quantities of rolling resistance force for several front caster sizes presented by Frank and Abel were on average $16 \mathrm{~N}$ for a load of $800 \mathrm{~N}$, compared with an average of $5 \mathrm{~N}$ for a load of $688 \mathrm{~N}$ (approximately) and 40 percent the total weight supported by the casters presented in this study. This discrepancy could be explained by the fact that Frank and Abel used a special trolley with four identical "test wheels" [33] (caster wheels) for their drag tests; thus, the entire weight was supported by these small wheels (average diameter $=147.64 \mathrm{~mm}$ ), where the rolling resistance coefficient is, theoretically, larger. Brubaker, on the other hand, reported a rolling resistance force of around $13 \mathrm{~N}$ when the pair of caster wheels (8 in.) supported 40 percent of a load of $800 \mathrm{~N}$ [29]. Compared with a similar test condition presented in this study, a value of $4.12 \mathrm{~N}$ was reported when testing the largest caster (6 in.) and same weight distribution. This difference in the rolling resistance values could be attributed to different sizes in caster wheels, a change in load (more than $100 \mathrm{~N}$ ), and a different material used [32] in the tires of the casters and rear wheels, since Brubaker used gray rubber [29].

\section{Weight Distribution}

Validating the second hypothesis, the weight distribution factor showed a significant effect on the rolling resistance force, regardless of the caster set installed in the wheelchair. This reinforces what other authors have reported in similar articles [24,29-30,34]. The differences between the drag force' values presented could be attributed to distinct drag test methods between studies. The results reported in this article should be taken merely to compare the effects of the independent variables and not as absolute values. By propelling over soft or hard surfaces or smooth or rough surfaces, the benefits of moving the center of gravity closer to the rear axle could increase or decrease significantly [31,35].

The results presented in this study show that the size of the caster wheels is not nearly as critical as the weight distribution for reducing rolling resistance. 


\section{Limitations}

The position of the caster stem was not controlled, regardless of the size of the caster wheel installed. If the caster stem is not perpendicular to the floor, the chair may be difficult to keep in a straight line, thus increasing the rolling resistance.

The angle differences between the caster stem and the normal angle of the rolling surface were roughly $4^{\circ}$, $1.8^{\circ}$, and $0^{\circ}$ for the 4 in., 5 in., and 6 in. caster sets, respectively. A subsequent test asserted a percent variation in the drag force of 6.5 percent for the $4 \mathrm{in}$. caster set and 1.7 percent for the 5 in. caster set when adjusting the stem incline to a perpendicular orientation relative to the rolling surface, demonstrating the small influence of the caster stem angle variable in this study.

This study only showed the effects of caster diameter and weight distribution on a relatively smooth treadmill surface, where the wheelchair moves in a straight line. It is not valid for outdoor rough surfaces. Future research needs to address the minimal wheel size for practical use over outdoor surfaces.

\section{CONCLUSIONS}

Smaller caster wheel diameters will increase the overall drag forces during wheelchair propulsion. However, caster size will not bring any significant difference in the drag force if the wheelchair user has 30 percent or less of his or her weight supported by the caster wheels (70\% or more by rear wheels). The largest caster tested did not show a significant difference in the rolling resistance force measured. Hence, casters larger than 5 in. are not necessarily better. More important for reducing rolling resistance is the amount of weight the front casters bear. Weight distribution will affect the drag force regardless of the set of casters used, allowing the wheelchair user and clinician to choose the one that suits the user's greatest needs as long as they sit in a rearward position. An optimal combination of both variables must be sought, taking into consideration that weight distribution is more important than caster wheel size in order to reduce energy losses on smooth surfaces.

\section{ACKNOWLEDGMENTS}

Author Contributions:

Study concept and design: B. Sawatzky, R. Zepeda, F. Chan.
Data collection: R. Zepeda.

Analysis and interpretation of data: B. Sawatzky, R. Zepeda, F. Chan. Drafting of manuscript: B. Sawatzky, R. Zepeda.

Critical revision of manuscript for important intellectual content: F. Chan.

Obtained funding: B. Sawatzky, R. Zepeda.

Financial Disclosures: The authors have declared that no competing interests exist.

Funding/Support: This material was based on work supported by the International Collaboration on Repair Discoveries (Vancouver,

Canada) and the Mitacs (Vancouver, Canada).

Additional Contributions: The authors would like to thank Mehdi Eshraghi for his collaboration during the data acquisition process. R. Zepada is now with the Department of Mechanical Engineering, University of British Columbia, Vancouver, Canada.

\section{REFERENCES}

1. Pollack ME. Intelligent technology for an aging population: The use of AI to assist elders with cognitive impairment. AI Mag. 2005;26(2):9-24.

2. Shields M. Fauteuils roulants et autres appareils d'aide à la mobilité. Rapports sur la santé. Statistique Canada. 2004;15(3):41-46. French.

3. Vignier N, Ravaud JF, Winance M, Lepoutre FX, Ville I. Demographics of wheelchair users in France: Results of national community-based handicaps-incapacités-dépendance surveys. J Rehabil Med. 2008;40(3):231-39.

[PMID:18292927]

http://dx.doi.org/10.2340/16501977-0159

4. Sedgwick M, Frank AO, Kemp P, Gage P, editors Improving services for wheelchair users and carers. London (UK): NHS; 2005. 36 p.

5. Brault MW. Americans with disabilities: 2010. Washington (DC): U.S. Census Bureau; 2012.

6. de Groot S, Vegter RJ, van der Woude LH. Effect of wheelchair mass, tire type and tire pressure on physical strain and wheelchair propulsion technique. Med Eng Phys. 2013; 35(10):1476-82. [PMID:23642660]

http://dx.doi.org/10.1016/j.medengphy.2013.03.019

7. van der Woude LH, Veeger HE, Dallmeijer AJ, Janssen TW, Rozendaal LA. Biomechanics and physiology in active manual wheelchair propulsion. Med Eng Phys. 2001; 23(10):713-33. [PMID:11801413] http://dx.doi.org/10.1016/S1350-4533(01)00083-2

8. Samuelsson KA, Tropp H, Gerdle B. Shoulder pain and its consequences in paraplegic spinal cord-injured, wheelchair users. Spinal Cord. 2004;42(1):41-46. [PMID:14713943] http://dx.doi.org/10.1038/sj.sc.3101490

9. Fullerton HD, Borckardt JJ, Alfano AP. Shoulder pain: A comparison of wheelchair athletes and nonathletic wheelchair users. Med Sci Sports Exerc. 2003;35(12):1958-61. 


\section{[PMID:14652488]}

http://dx.doi.org/10.1249/01.MSS.0000099082.54522.55

10. Curtis KA, Drysdale GA, Lanza RD, Kolber M, Vitolo RS, West R. Shoulder pain in wheelchair users with tetraplegia and paraplegia. Arch Phys Med Rehabil. 1999;80(4):453-57. [PMID:10206610] http://dx.doi.org/10.1016/S0003-9993(99)90285-X

11. Curtis KA, Roach KE, Applegate EB, Amar T, Benbow CS, Genecco TD, Gualano J. Development of the Wheelchair User's Shoulder Pain Index (WUSPI). Paraplegia. 1995;33(5):290-93. [PMID:7630657]

http://dx.doi.org/10.1038/sc.1995.65

12. Sonenblum SE, Sprigle S, Lopez RA. Manual wheelchair use: Bouts of mobility in everyday life. Rehabil Res Pract. 2012;2012:753165. [PMID:22848837]

13. Sawatzky B, DiGiovine C, Berner T, Roesler T, Katte L. The need for updated clinical practice guidelines for preservation of upper extremities in manual wheelchair users: A position paper. Am J Phys Med Rehabil. 2015;94(4): 313-24. [PMID:25299526]

http://dx.doi.org/10.1097/PHM.0000000000000203

14. Veeger HE, van der Woude LH, Rozendal RH. Effect of handrim velocity on mechanical efficiency in wheelchair propulsion. Med Sci Sports Exerc. 1992;24(1):100-7.

[PMID:1548983]

http://dx.doi.org/10.1249/00005768-199201000-00017

15. van der Woude LH, de Groot G, Hollander AP, van Ingen Schenau GJ, Rozendal RH. Wheelchair ergonomics and physiological testing of prototypes. Ergonomics. 1986; 29(12):1561-73. [PMID:3102225] http://dx.doi.org/10.1080/00140138608967269

16. van der Woude LH, Hendrich KM, Veeger HE, van Ingen Schenau GJ, Rozendal RH, de Groot G, Hollander AP. Manual wheelchair propulsion: Effects of power output on physiology and technique. Med Sci Sports Exerc. 1988; 20(1):70-78. [PMID:2963939] http://dx.doi.org/10.1249/00005768-198802000-00011

17. van der Woude LH, Veeger HE, Rozendal RH, van Ingen Schenau GJ, Rooth F, van Nierop P. Wheelchair racing: Effects of rim diameter and speed on physiology and technique. Med Sci Sports Exerc. 1988;20(5):492-500.

[PMID:3193866] http://dx.doi.org/10.1249/00005768-198810000-00011

18. Veeger D, van der Woude LH, Rozendal RH. The effect of rear wheel camber in manual wheelchair propulsion. J Rehabil Res Dev. 1989;26(2):37-46. [PMID:2724151]

19. Veeger HE, van der Woude LH, Rozendal RH. Load on the upper extremity in manual wheelchair propulsion. J Electromyogr Kinesiol. 1991;1(4):270-80. [PMID:20870518] http://dx.doi.org/10.1016/1050-6411(91)90014-V

20. Coyle EF, Sidossis LS, Horowitz JF, Beltz JD. Cycling efficiency is related to the percentage of type I muscle fibers.
Med Sci Sports Exerc. 1992;24(7):782-88. [PMID:1501563]

http://dx.doi.org/10.1249/00005768-199207000-00008

21. Cavagna GA, Kaneko M. Mechanical work and efficiency in level walking and running. J Physiol. 1977;268(2):467-81. [PMID:874922]

http://dx.doi.org/10.1113/jphysiol.1977.sp011866

22. Donovan CM, Brooks GA. Muscular efficiency during steady-rate exercise. II. Effects of walking speed and work rate. J Appl Physiol. 1977;43(3):431-39. [PMID:914714]

23. Beekman CE, Miller-Porter L, Schoneberger M. Energy cost of propulsion in standard and ultralight wheelchairs in people with spinal cord injuries. Phys Ther. 1999;79(2): 146-58. [PMID:10029055]

24. Cowan RE, Nash MS, Collinger JL, Koontz AM, Boninger ML. Impact of surface type, wheelchair weight, and axle position on wheelchair propulsion by novice older adults. Arch Phys Med Rehabil. 2009;90(7):1076-83.

[PMID:19577019]

http://dx.doi.org/10.1016/j.apmr.2008.10.034

25. Gordon J, Kauzlarich JJ, Thacker JG. Tests of two new polyurethane foam wheelchair tires. J Rehabil Res Dev. 1989;26(1):33-46. [PMID:2918486]

26. Sawatzky BJ, Kim WO, Denison I. The ergonomics of different tyres and tyre pressure during wheelchair propulsion. Ergonomics. 2004;47(14):1475-83. [PMID:15697064] http://dx.doi.org/10.1080/00140130412331290862

27. Rabinowicz E. Friction and wear of materials. 2nd ed. New York (NY): Wiley; 1995. 336 p.

28. Sprigle S, Huang M. Impact of mass and weight distribution on manual wheelchair propulsion torque. Assist Technol. 2015;27(4):226-35. [PMID:26691562] http://dx.doi.org/10.1080/10400435.2015.1039149

29. Brubaker CE. Wheelchair prescription: An analysis of factors that affect mobility and performance. J Rehabil Res Dev. 1986;23(4):19-26. [PMID:3820118]

30. Tomlinson JD. Managing maneuverability and rear stability of adjustable manual wheelchairs: An update. Phys Ther. 2000;80(9):904-11. [PMID:10960938]

31. de Groot S, Zuidgeest M, van der Woude LH. Standardization of measuring power output during wheelchair propulsion on a treadmill Pitfalls in a multi-center study. Med Eng Phys. 2006;28(6):604-12. [PMID:16300988] http://dx.doi.org/10.1016/j.medengphy.2005.09.004

32. Kauzlarich JJ, Thacker JG. Wheelchair tire rolling resistance and fatigue. J Rehabil Res Dev. 1985;22(3):25-41. [PMID:3835263] http://dx.doi.org/10.1682/JRRD.1985.07.0025

33. Frank TG, Abel EW. Measurement of the turning, rolling and obstacle resistance of wheelchair castor wheels. J Biomed Eng. 1989;11(6):462-66. [PMID:2811344] http://dx.doi.org/10.1016/0141-5425(89)90040-X 
34. Boninger ML, Baldwin M, Cooper RA, Koontz A, Chan L. Manual wheelchair pushrim biomechanics and axle position. Arch Phys Med Rehabil. 2000;81(5):608-13. [PMID:10807100] http://dx.doi.org/10.1016/S0003-9993(00)90043-1

35. Bascou J, Sauret C, Pillet H, Vaslin P, Thoreux P, Lavaste F. A method for the field assessment of rolling resistance properties of manual wheelchairs. Comput Methods Biomech Biomed Engin. 2013;16(4):381-91. [PMID:22260153] http://dx.doi.org/10.1080/10255842.2011.623673

Submitted for publication May 3, 2015. Accepted in revised form November 30, 2015.
This article and any supplementary material should be cited as follows:

Zepeda R, Chan F, Sawatzky B. The effect of caster wheel diameter and mass distribution on drag forces in manual wheelchairs. J Rehabil Res Dev. 2016;53(6):893-900. http://dx.doi.org/10.1682/JRRD.2015.05.0074

ORCID: Bonita Sawatzky, PhD: 0000-0002-8901-2301

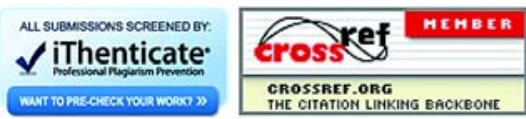

